\title{
Morphology and Size Distribution of Naturally Occurring Asbestos using TEM in Landscape Rock in Parks
}

\author{
Sook-Nye Chung ${ }^{\dagger}$, Ji-Sung Kim, Ki-Kyo Lim, Sun-Jeong Won, Ji-Young Lee, Kwang-Rae Kim, \\ Jin-Ho Shin, and Yong-Seung Shin
}

Seoul Metropolitan Government Research Institute of Public Health and Environment, 30 Janggunmaeul 3-gil, Gwacheon-si, Gyeonggi-do, 13818, Korea

Received January 28, 2021 / Revised March 11, 2021 / Accepted March 15, 2021

\begin{abstract}
This study provided data that can be used to discriminate asbestiform and non-asbestiform amphiboles contained in landscaping rocks in recreational parks. The length and width of fibers being at least $5 \mu \mathrm{m}$ long and with a minimum aspect ratio of 3:1 were measured using a transmission electron microscope and compared to an asbestos reference sample. The park samples were thicker than $1 \mu \mathrm{m}$ (average $1.9 \mu \mathrm{m}$ ), while the Health and Safety Executive (HSE) reference sample averaged $0.3 \mu \mathrm{m}$ in width, with $100 \%$ being thinner than $1.0 \mu \mathrm{m}$. The average aspect ratios were 7.1 for the park samples and 67.1 for the HSE reference sample. Based on these distributions, the amphibole fibers in sampled landscape rocks were thicker and had a lower aspect ratio than the reference sample. These results suggest that actinolite fibers in sampled landscape rocks cannot be classified into commercial-grade asbestos. This study can contribute to public policy for managing and controlling landscaping rocks containing naturally occurring asbestos (NOA) and be used to communicate the possible resulting health risks.
\end{abstract}

Key words: Naturally Occurring Asbestos(NOA), Amphibole, Width, Aspect ratio, Landscape rock

\section{1. 서 론}

석면은 석면형태(asbestiform)로 산출되는 규산염광물 로 지질학적 작용에 의해 지구의 지각에 자연적으로 생 성된 광물이다. 일반적으로 '석면'이라고 하면 상업적으 로 널리 사용된 백석면, 청석면, 갈석면, 안소필라이트 석면, 트레모라이트석면, 악티노라이트석면의 여섯 종 의 광물을 지칭한다. 이 중 사문석계에 속하는 백석면 을 제외한 나머지 다섯 가지 석면은 각섬석계 광물에 속한다. 각섬석은 지각을 이루는 광물 중 약 $5 \%$ 를 차 지하는 광물로 지각 중에서 광범위하게 산출될 수 있 고, 열수, 변성 등 광물 생성 당시의 지질환경에 따라
다양한 형태로 산출될 수 있다. ${ }^{1)}$

석면형태(asbestiform)란 상업적으로 사용된 여섯 종 류의 석면에서 보이는 것과 같은 매우 길고 가는 섬유 형태로 생성되는 광물의 결정습성 중의 하나이다. ${ }^{2)}$ 광 학현미경으로 관찰 시 석면형태는 길이가 $5 \mu m$ 보다 긴 섬유들에 대해 평균 길이 대 너비의 비율(aspect ratio) 이 20:1에서 100:1 또는 그 이상이고, 일반적으로 개별 섬유의 너비가 $0.5 \mu \mathrm{m}$ 이하로 매우 가늘며, 그 외 섬유 가 평행하게 모여 있거나 끝 부분이 각각의 섬유로 넓 게 퍼진 섬유다발, 헝클어진 섬유들의 덩어리 또는 섬 유나 다발의 굴곡진 형태 등의 특징이 있다. 또한 길이 대 너비의 비율 <20:1인 입자가 대부분이고 별도의 석

\footnotetext{
${ }^{\dagger}$ To whom correspondence should be addressed.
}

Tel: 82-2-570-3172, Fax: 82-2-570-3177, E-mail: sugene@seoul.go.kr 
면형태의 특성이 발견되지 않는 시료는 석면으로 간주 되어서는 안 된다고 규정되어있다.3)

미국 직업안전 및 건강관리청(OSHA)에서는 비석면 형태의 트레모라이트, 앤소필라이트 그리고 악티노라이 트는 석면과 같은 건강유해성이 충분히 입증되지 않았 다는 역학적 연구결과를 바탕으로 이들 비석면형태의 각섬석계 광물을 석면에서 제외시켰다. ${ }^{4)}$ 또한 석면형태 와 독성 관련 몇몇 연구결과, 비석면형태의 각섬석계 광물은 석면형태의 것과 비교할 때 훨씬 덜 유해하고, 폐암이나 중피종을 증가시키지 않는 것으로 나타났다.5-7)

광물학적 넓은 의미에서 모든 석면은 자연발생석면 (naturally occurring asbestos)이지만, 광산 등에서 채취 하여 상업적으로 이용된 석면과 구별하여 암반이나 토 양에서 자연 그대로의 상태로 발견되는 석면을 자연발 생석면으로 정의하기도 한다. ${ }^{8-11)}$ 공원 조경석은 자연발 생석면 중의 하나로 조경석 중 석면은 석면함유가능물 질 분석방법인 환경부고시에 따라 분석한다. ${ }^{2)}$ 석면으 로 분류되는 섬유상 광물은 공기 중 석면 계수기준과 일관성을 유지하기 위해 길이 대 너비의 비율 $3: 1$ 이상 인 입자를 대상으로 한다. 조경석과 같은 고형시료 분 석에 공기 중 석면 계수기준을 적용하면 고형석면 분석 기준인 길이 대 너비의 비율 $20: 1$ 이상의 석면입자뿐만 아니라 기다란 비석면형태(elongated non-asbestiform)의 각섬석계 광물입자도 석면으로 분류될 가능성이 있다.

현재까지 석면형태와 비석면형태를 구분하는 명확한 분석기준은 확립되지 않았지만 섬유의 너비, 길이 대 너 비 비율 등의 크기분포나 형태적 특성을 살펴 석면형태 와 비석면형태의 구분을 시도한 연구들이 있다.,213-15) 의 도적으로 석면을 첨가하지 않은 자연발생석면의 경우 에는 정확한 석면분석을 위하여 석면형태인지에 대한 구분이 필요하다. 본 연구에서는 편광현미경으로 확인 결과 석면을 함유한 것으로 조사된 공원 조경석을 채 취하여 투과전자현미경으로 길이 $5 \mu m$ 이상이고 길이 대 너비 비율 $3: 1$ 이상인 입자의 길이와 너비를 측정하 여 석면 표준시료와 비교하여 공원 조경석에 함유된 악 티노라이트가 석면형태인지 비석면형태인지 구분하고자 하였다.

\section{2. 재료 및 방법}

\section{1. 연구대상}

서울시 석면관리를 위한 자연석 석재 석면 함유 실 태조사 ${ }^{16)}$ 에 따르면 서울시 소재 공원 중 서울시에서 관
리하는 1890 개 공원 중 674 개 공원에 조경석이 설치되 어있고, 이 중 53개 공원이 석면함유 의심 조경석을 보 유하고 있는 것으로 파악되었다. 석면함유 의심 조경석 이 있는 공원에 대해 총 225 개 지점에서 시료를 채취 하여 정밀조사를 실시한 결과 21 개 공원에서 석면이 검 출되었다. 본 연구에서는 21 개 공원 중 석면을 함유한 것으로 판정된 조경석이 2지점 이상 발견된 공원 중 5 개의 공원을 연구대상으로 선정하였다.

\section{2. 시료채취 및 분석}

공원에 분포한 조경석의 표면을 육안으로 확인하여 석면으로 의심되는 물질 또는 섬유상 형태의 물질이 분 포하고 있는 조경석에서 공원별로 3 10개의 고형시료 를 채취하였다. 시료는 편광현미경과 투과전자현미경을 이용하여 분석하였다.

검출된 섬유상 입자(길이 $\geq 5 \mu m$, 길이 대 너비 비율 $\geq 3: 1)$ 의 크기분포와 형태적 특성을 투과전자현미경으로 관찰하기 위해 조경석 시료를 공원별로 1 개씩 선택하 였다. 미국 $\mathrm{EPA}$ 의 고형시료 석면분석방법 중 전자현미 경분석을 위한 시편제작방법에 따라 조경석 시료를 막 자사발로 분쇄 후 소량의 아세톤에 혼합하고, 초음파분 산기에서 약 5 분간 분산시켜 마이크로피펫으로 시료 일 부를 취해 탄소 코팅된 그리드에 올려 건조시켰다. ${ }^{3)}$

투과전자현미경(Tecnai G2, $120 \mathrm{keV}$, FEI company, Hillsboro, USA)을 이용하여 섬유상 입자 중 에너지분산 형 X선 분광기(energy dispersive X-ray spectrometer, $\mathrm{EDS})$ 스펙트럼과 제한시야 회절패턴(selected area diffraction pattern, SAED)으로 화학조성과 결정구조를 분석한 결과 석면과 동일한 것으로 확인된 입자의 길 이와 너비를 측정하였다. 길이는 입자의 최대 길이를 기록하고, 너비는 입자의 대표되는 점에서 길이에 수직 이 되도록 측정하여 기록하였다. 결정구조 분석을 위한 제한시야 회절패턴에서는 d-spacing이 $5.3 \AA$ 인 선이 반복적으로 나타나는 것을 기준으로 각섬석계 입자임 을 확인하고, $\mathrm{EDS}$ 스펙트럼으로 $\mathrm{Si}$ 피크의 값이 약 5,000 counts 이상이 될 때까지 얻은 원소조성 결과를 바탕으로 광물의 종류를 구분하였다. 특히 화학조성이 악티노라이트와 매우 유사한 magnesio-hornblend와의 구분을 위해 $\mathrm{Al} / \mathrm{Si}$ 비율 $1: 10$ 을 기준으로 그 이하인 입 자만 악티노라이트로 판별하였다. 입자의 형태적 특성 을 파악하기 위해 입자의 길이방향과 끝부분의 형태를 관찰하여 평행하고 규칙적인 사각모양인지 아니면 울 퉁불퉁하고 불규칙한 모양인지 살펴보았다. 영국안전보 
건청의 악티노라이트석면 표준시료(HSE reference actinolite asbestos, Health \& Safety Laboratory, UK) 를 석면형태시료로 선택하여 조경석 시료와 같은 방법 으로 전처리하여 비교분석하였다.

\section{3. 결과 및 고찰}

\section{1. 편광현미경 분석결과}

조경석 표면을 육안으로 확인한 뒤 석면함유 의심부 위 29곳의 고형시료를 채취하여 석면함유가능물질 분 석방법에 따라 편광현미경으로 분석한 결과, 15 개 시료 (약 $52 \%$ )에서 석면이 검출되었다. 공원별로 석면이 검 출된 고형시료 1 개씩을 선택하여 총 5 개 시료를 투과 전자현미경으로 관찰한 결과 악티노라이트가 검출되었 다(Table 1).

\section{2. 형태적 특성}

공원 조경석 시료(a)와 석면 표준시료(b)에서 관찰되 는 대표적인 입자형태는 Fig. 1과 같았다. 공원 조경석 시료는 두껍고 반듯하지 않은 입자가 대부분으로, 곧은

Table 1. Characteristics of bulk sample from the landscape rock

\begin{tabular}{cccc}
\hline \hline Park & $\begin{array}{c}\text { Number of } \\
\text { bulk samples }\end{array}$ & $\begin{array}{c}\text { Number of } \\
\text { asbestos-containing } \\
\text { bulk samples }\end{array}$ & $\begin{array}{c}\text { Asbestos type } \\
\text { by TEM }\end{array}$ \\
\hline 1 & 4 & 2 & Actinolite \\
2 & 6 & 3 & Actinolite \\
3 & 10 & 4 & Actinolite \\
4 & 4 & 3 & Actinolite \\
5 & 5 & 3 & Actinolite \\
\hline Total & 29 & 15 & Actinolite \\
\hline
\end{tabular}

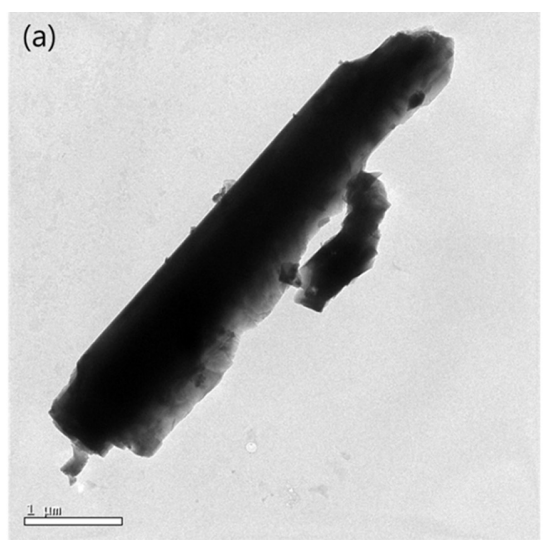

형태의 가늘고 긴 석면 표준시료와 형태적으로 확연한 차이를 보였다. 입자 끝부분의 형태 역시 공원 조경석 시료의 경우 대부분 쪼개짐에 의한 불규칙한 형태를 보인 반면 HSE 석면 표준시료의 경우 사각형 형태를 보였다.

\section{3. 크기분포}

\subsection{1. 너비와 길이 대 너비 비율 분포}

Table 2와 Table 3은 조경석에서 검출된 석면섬유의 너비 분포와 길이 대 너비 비율의 분포 특성을 석면 표준시료의 특성과 비교하여 나타낸 것이다. 조경석 시 료의 경우 섬유의 평균 너비는 $1.5 \sim 2.1 \mu \mathrm{m}$ 이고, 너비 $0.5 \mu \mathrm{m}$ 및 $1.0 \mu \mathrm{m}$ 이하인 섬유의 비율은 각각 $2 \sim 7 \%$ 와 $11 \sim 31 \%$ 이었다. HSE 석면 표준시료의 경우 평균 너비 는 $0.3 \mu \mathrm{m}$ 이고, 너비 $0.5 \mu \mathrm{m}$ 및 $1.0 \mu \mathrm{m}$ 이하인 섬유의 비율은 각각 $98 \%$ 와 $100 \%$ 로 나타났다(Table 2).

조경석 시료의 경우 섬유의 평균 길이 대 너비 비율 은 6.1 8.2이고, 길이 대 너비 비율이 $10: 1$ 및 $20: 1$ 이

Table 2. Width data of $5 \mu \mathrm{m}$ actinolite and longer with a minimum aspect ratio of $3: 1$

\begin{tabular}{|c|c|c|c|c|}
\hline Park & $\begin{array}{l}\text { Particles } \\
\text { analyzed }\end{array}$ & $\begin{array}{l}\text { Mean } \pm \text { SD } \\
\quad(\mu \mathrm{m})\end{array}$ & $\begin{array}{c}\text { Width } \leq \\
0.5 \mu \mathrm{m} \\
(\%)\end{array}$ & $\begin{array}{c}\text { Width } \leq \\
1.0 \mu \mathrm{m} \\
(\%)\end{array}$ \\
\hline 1 & 100 & $2.1 \pm 1.2$ & 2 & 11 \\
\hline 2 & 100 & $1.9 \pm 1.2$ & 6 & 22 \\
\hline 3 & 100 & $1.5 \pm 0.8$ & 7 & 31 \\
\hline 4 & 100 & $2.1 \pm 1.1$ & 2 & 13 \\
\hline 5 & 100 & $1.8 \pm 0.9$ & 2 & 13 \\
\hline $\begin{array}{c}\text { HSE reference } \\
\text { actinolite asbestos }\end{array}$ & 100 & $0.3 \pm 0.2$ & 98 & 100 \\
\hline
\end{tabular}

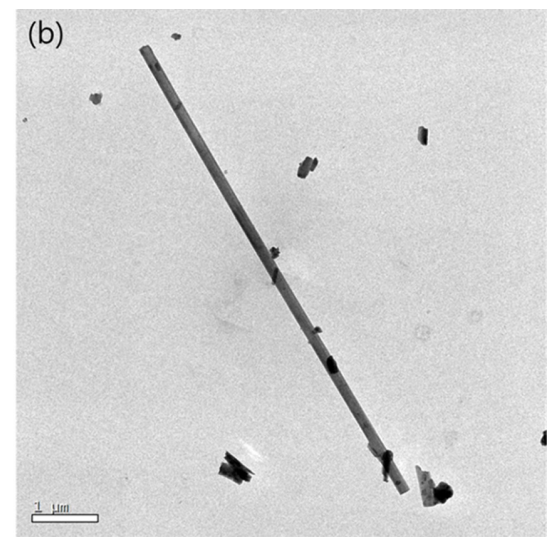

Fig. 1. Examples of particles with nonparallel sides and irregular termination, (a) landscape rock, and parallel sides and square termination, (b) HSE reference actinolite asbestos. 
Table 3. Aspect ratio data of $5 \mu \mathrm{m}$ actinolite and longer with a minimum aspect ratio of $3: 1$

\begin{tabular}{ccccc}
\hline \hline Park & $\begin{array}{c}\text { Particles } \\
\text { analyzed }\end{array}$ & Mean \pm SD & $\begin{array}{l}\text { Aspect } \\
\text { ratio } \geq \\
10: 1(\%)\end{array}$ & $\begin{array}{c}\text { Aspect } \\
\text { ratio } \geq \\
20: 1(\%)\end{array}$ \\
\hline 1 & 100 & $6.1 \pm 2.7$ & 7 & 0 \\
2 & 100 & $8.0 \pm 10.6$ & 9 & 5 \\
3 & 100 & $8.2 \pm 5.5$ & 21 & 5 \\
4 & 100 & $6.8 \pm 3.4$ & 14 & 2 \\
5 & 100 & $6.4 \pm 3.4$ & 10 & 1 \\
$\begin{array}{c}\text { HSE reference } \\
\text { actinolite asbestos }\end{array}$ & 100 & $67.1 \pm 44.8$ & 99 & 96 \\
\hline
\end{tabular}

상인 섬유의 비율은 각각 7 21\% 및 $0 ~ 5 \%$ 로 나타났다. HSE 석면 표준시료의 경우 평균 길이 대 너비 비율은 67.1이고, 길이 대 너비 비율 $10: 1$ 및 20:1 이상인 섬 유의 비율은 각각 $99 \%$ 및 $96 \%$ 로 나타났다(Table 3).

5 개 조경석 시료의 너비 평균값은 $1.9 \mu m$ 로 Wylie가 역학조사, 동물실험결과 등을 바탕으로 암이나 중피종 같은 인체유해성과 관련이 있다고 보고한 너비 $1 \mu m$ 이 하 ${ }^{5}$ 보다 약 2 배 정도 두껍다. 길이 대 너비 비율 평균 값은 7.1로 고형석면 분석기준인 20:1을 만족시키지 못 하는 섬유가 95 100\%로 대부분이며 별도의 석면형태 의 특성이 발견되지 않는 않으므로 US EPA 고형시료 석면분석방법 중 석면형태 정의에 따르면 비석면형태 인 것으로 간주된다.3) 또한 Chatfield가 제안한 석면형태 의 기준인 너비 $1.5 \mu m$ 이하, 길이 대 너비 비율 $20: 1$ 이상을 만족시키는 입자는 $0 \sim 5 \%$ 에 불과해 대부분 비 석면형태로 분류된다. ${ }^{13)}$

관찰된 섬유상 입자의 너비와 길이 대 너비 비율의 분포를 나타낸 Fig. 2는 조경석 시료와 석면 표준시료 사이의 뚜렷한 차이가 있음을 보여준다. 석면 표준시료
Table 4. Regression equation and correlation coefficient of $\log$ width vs. log length

\begin{tabular}{ccc}
\hline \hline Park & $\begin{array}{c}\text { Regression equation } \\
\text { Log width } Y=f(\text { Log length })\end{array}$ & $\begin{array}{c}\text { Correlation } \\
\text { coefficient }\end{array}$ \\
\hline 1 & $Y=0.8925 X-0.6437$ & 0.786 \\
2 & $Y=0.7521 X-0.5517$ & 0.643 \\
3 & $Y=0.8596 X-0.7232$ & 0.627 \\
4 & $Y=0.7564 X-0.5384$ & 0.691 \\
5 & $Y=0.7055 X-0.4801$ & 0.530 \\
HSE reference & $Y=0.2456 X-0.8328$ & 0.297 \\
actinolite asbestos & & \\
\hline
\end{tabular}

와 조경석 시료의 너비평균값과 표준편차는 각각 $0.3 \pm 0.2 \mu \mathrm{m}$ 과 $1.9 \pm 1.1 \mu \mathrm{m}$ 로 석면 표준시료의 너비는 조경석 시료에 비해 훨씬 더 가늘고 그 분포가 균일하 다. 석면 표준시료와 조경석 시료의 길이 대 너비 비율 평균값과 표준편차는 각각 $67.1 \pm 44.8$ 과 $7.1 \pm 5.9$ 로, 석면 표준시료의 경우 길이와 상관없이 너비 값이 거의 일 정하여 길이 대 너비 비율이 큰 변동을 보이는 반면 조 경석 시료는 길이가 증가함에 따라 너비도 증가하는 경 향을 보여 석면 표준시료에 비해 길이 대 너비 비율이 작고 균일한 분포를 보이는 것으로 판단된다.

3.3.2. 너비와 길이, 길이 대 너비의 비율과 길이의 관계

조경석 시료와 $\mathrm{HSE}$ 석면 표준시료의 $\log$ 너비 $(Y)$ 와 $\log$ 길이 $(X)$ 에 대한 회귀방정식과 상관계수를 Table 4 에 나타내었다. Siegrsit and Wylie는 석면입자의 형태 를 구분하는 연구에서 석면섬유와 비석면형 광물입자 의 가장 명확한 차이는 석면섬유의 너비는 길이와 상 관없이 상대적으로 일정한 반면, 비석면형 광물입자의 너비는 길이의 함수로 나타난다는 점이라고 밝혔다. ${ }^{17)}$
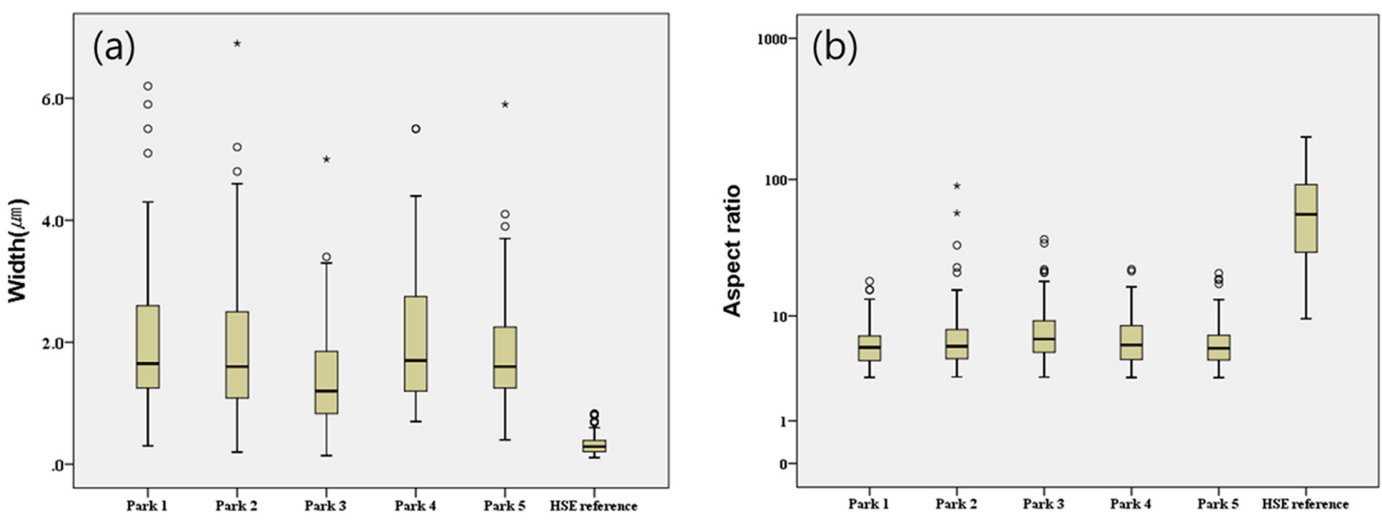

Fig. 2. Box plot of width (a) and aspect ratio (b) for landscape rocks in parks and HSE reference actinolite asbestos. 
Table 5. Regression equation and correlation coefficient of $\log$ aspect ratio vs. log length

\begin{tabular}{ccc}
\hline Park & $\begin{array}{c}\text { Regression equation } \\
\text { Log aspect ratio } \\
=f(\log \text { length })\end{array}$ & $\begin{array}{c}\text { Correlation } \\
\text { coefficient }\end{array}$ \\
\hline 1 & $Y=0.1075 X+0.6437$ & 0.117 \\
2 & $Y=0.2479 X+0.5517$ & 0.134 \\
3 & $Y=0.1404 X+0.7232$ & 0.083 \\
4 & $Y=0.2436 X+0.5384$ & 0.234 \\
5 & $Y=0.2945 X+0.4801$ & 0.292 \\
HSE reference & $Y=0.7544 X+0.8328$ & 0.718 \\
actinolite asbestos & & \\
\hline
\end{tabular}

석면 표준시료의 경우 길이와 상관없이 너비가 일정하 여 길이와 너비의 상관계수는 0.297 로 상관관계가 낮고, 공원 조경석에서 나온 입자들의 경우 길이가 증가함에 따라 너비가 함께 증가하여 상관계수는 0.530 0.786으 로 길이와 너비가 비교적 높은 상관관계를 나타내므로 공원 조경석 시료는 비석면형 광물입자의 특성을 보이 는 것으로 판단된다.

조경석 시료와 $\mathrm{HSE}$ 석면 표준시료의 $\log$ 길이 대 너비의 비율 $(Y)$ 과 $\log$ 길이 $(X)$ 에 대한 회귀방정식과 상 관계수를 Table 5에 나타내었다. Wylie는 석면시료에 대한 섬유 길이와 길이 대 너비 비율에 관한 연구에서 $\log$ 길이 대 너비 비율 $(Y)$ 과 $\log$ 길이 $(X)$ 에 대한 회귀 방정식의 기울기를 섬유화 지표로 정의하고, 석면시료 는 섬유화가 잘 발달되어 개별 섬유들이 거의 일정한 너비를 가지고 있어 기울기가 1 에 가깝다는 연구결과 를 발표했다. ${ }^{18)} \mathrm{HSE}$ 석면 표준시료의 $\log$ 길이 대 너 비 비율 $(Y)$ 과 $\log$ 길이 $(X)$ 의 회귀방정식의 기울기가 0.7544 로 1 에 가까운 반면 공원 조경석에서 나온 입자 들의 기울기는 $0.1075 \sim 0.2945$ 로 0 에 가깝다. 이는 공 원 조경석 시료의 경우 입자의 길이가 증가함에 따라 너비가 증가하여 길이 대 너비의 비율이 거의 동일하 다는 것을 의미하는 것으로 석면시료와 구분되는 비석 면형 광물입자의 특성이라고 할 수 있다.

\section{4. 결 론}

본 연구에서는 서울시에 소재한 공원 조경석에서 검 출되는 악티노라이트를 대상으로 크기 분포와 형태적 특성을 관찰하였다. 석면형태 구분을 위해 입자의 형 태, 너비와 길이 대 너비 비율 분포 등을 분석하여 석 면 표준시료와 비교한 결과 연구대상 5 개 공원 조경석 에 함유된 악티노라이트는 석면 표준시료와 크기분포
에 차이를 보였으며 전형적인 석면형태로 구분할 수 없 다. 비석면형태의 각섬석계 석면은 발암성을 보이지 않 는다는 석면형태와 독성 관련 연구결과 ${ }^{4-7)}$ 와 조경석에 함유된 자연발생석면의 크기 분포 및 형태적인 특성을 분석한 본 연구결과는 합리적인 조경석 관리방안을 결 정하고, 조경석에 함유되어 있는 자연발생석면에 대해 불안감을 가진 시민들과의 리스크 커뮤니케이션에 자 료로 활용될 수 있을 것이다.

\section{참고문헌}

1. 정기영, 최진범, “투각삼석-양기석 계열 각섬석의 형태적 다양성과 자연 석면 평가에서의 의미”, 한국광물학회지, 2012, 25, 95-104.

2. D. R. Van Orden, K. A. Allison, and R. J. Lee, "Differentiating amphibole asbestos from non-asbestos in complex mineral environment", Indoor Built Environment, 2008, 17, 158-168.

3. US Environmental Protection Agency, EPA/600/R-93/ 116, "Method for the determination of asbestos in bulk building materials", 1993.

4. US Occupational Safety and Health and Administration, Federal Register, "Occupational exposure to asbestos, tremolite, anthophyllite and actinolite", 1992, 57, 2431024331

5. A. G. Wylie, K. F. Bailey, J. W. Kelseand, and R. J. Lee, "The importance of width in asbestos fiber carcinogenicity and its implications for public policy", American Industrial Hygiene Association Journal, 1993, 54, 239-252.

6. J. Addison and E. E. McConnell, "A review of carcinogenicity studies of asbestos and non-asbestos tremolite and other amphiboles", Regulatory Toxicology Pharmacology, 2008, 52, 187-199.

7. J. F. Gamble and G. W. Gibbs, "An evaluation of the risks of lung cancer and mesothelioma from exposure to amphibole cleavage fragments", Regulatory Toxicology Pharmacology, 2008, 52, 154-186.

8. M. Hendrickx, "Naturally occurring asbestos in eastern Australia: a review of geological occurrence, disturbance and mesothelioma risk", Environmental Geology, 2009, 57, 909-926.

9. 김정욱, 정명채, 김동진, 전기석, 이창환, “자연발생석면 분포지역의 효율적인 조사와 관리 방안", 지하수토양환 경, 2011, 16, 10-18.

10. R. J. Lee, B. R. Strohmeier, K. L. Bunker, and D. R. Van Orden, "Naturally occurring asbestos-a recurring public policy challenge", Hazardous Materials, 2008, 153, 1-21.

11. 환경부, “석면관리총람”, 2009. 
12. 환경부, 환경부고시 제2018-23호, “석면함유가능물질 조사분석을 위한 시료채취 및 분석방법”, 2008.

13. E. J. Chatfield, "A procedure for quantitative description of fibrosity in amphibole minerals", Paper presented at the ASTM international 2008 Johnson conference: Critical issues in monitoring asbestos, 2008, Burlington, VT, July, 14-18.

14. M. Harper, E. G. Lee, S. S. Doorn, and O. Hammond, "Differentiating non-asbestiform amphibole and amphibole asbestos by size characteristics", Journal of Occupational and Environmental Hygiene, 2008, 5, 761-770.

15. D. R. Van Orden, R. J. Lee, K. A. Allison, and J. Addi- son, "Width distributions of asbestos and non-asbestos amphibole minerals", Indoor Building Environment, 2009, $18,531-540$.

16. 양혁승, “서울시 석면관리를 위한 자연석 석재 석면 함유 실태조사", 서울녹색환경지원센터, 2013, 1-52.

17. H. G. Siegrist, and A. G. Wylie, "Characterizing and discriminating the shape of asbestos particles", Environmental Research, 1980, 23, 348-361.

18. A. G. Wylie, "Fiber length and aspect ratio of some selected asbestos samples", Annals of the New York Academy of Sciences, 1979, 330, 605-610. 